\title{
Integrated Modelling and Enhanced Utilization of Power-to-Ammonia for High Renewable Penetrated Multi-Energy Systems
}

Xu, Da; Zhou, Bin; Wu, Qiuwei; Chung, Chi Yung ; Li , Canbing; Huang, Sheng; Chen, She

Published in:

IEEE Transactions on Power Systems

Link to article, DOI:

10.1109/TPWRS.2020.2989533

Publication date:

2020

Document Version

Peer reviewed version

Link back to DTU Orbit

Citation $(A P A)$ :

Xu, D., Zhou, B., Wu, Q., Chung, C. Y., Li , C., Huang, S., \& Chen, S. (2020). Integrated Modelling and Enhanced Utilization of Power-to-Ammonia for High Renewable Penetrated Multi-Energy Systems. IEEE Transactions on Power Systems, 35(6), 4769 - 4780. https://doi.org/10.1109/TPWRS.2020.2989533

\section{General rights}

Copyright and moral rights for the publications made accessible in the public portal are retained by the authors and/or other copyright owners and it is a condition of accessing publications that users recognise and abide by the legal requirements associated with these rights.

- Users may download and print one copy of any publication from the public portal for the purpose of private study or research.

- You may not further distribute the material or use it for any profit-making activity or commercial gain

- You may freely distribute the URL identifying the publication in the public portal 


\title{
Integrated Modelling and Enhanced Utilization of Power-to-Ammonia for High Renewable Penetrated Multi-Energy Systems
}

\author{
Da Xu, Bin Zhou, Senior Member, IEEE, Qiuwei Wu, Senior Member, IEEE, Chi Yung Chung, Fellow, IEEE,
} Canbing Li, Senior Member, IEEE, Sheng Huang, She Chen

\begin{abstract}
This paper proposes an integrated model of power-toammonia (P2A) to exploit the inherent operational dispatchability of nitrogen-ammonia $\left(\mathrm{N}_{2}-\mathrm{NH}_{3}\right)$ cycles for high-renewable multienergy systems. In this model, the steady-state electrolytic process is mathematically formulated into a thermodynamic system based on thermo-electrochemical effects, and the long-term degradation process of $\mathrm{P2A}$ is transformed as the short-term degradation cost to characterize its cost-efficiency. Furthermore, the enhanced utilization of P2A is explored to form a renewable energy hub for coupled multi-energy supplies, and a coupling matrix is formulated for the optimal synergies of electrical, ammonia and thermal energy carriers. An iterative solution approach is further developed to schedule the hub-internal multi-energy conversion and storage devices for high-efficiency utilization of available hybrid solarwind renewables. Numerical studies on a stand-alone microgrid over a 24-hour scheduling periods are presented to confirm the effectiveness and superiority of the proposed methodology over regular battery and power-to-gas (P2G) storages on system operational economy and renewable energy accommodation.
\end{abstract}

Index Terms--Energy hub, integrated energy system, microgrid, power-to-ammonia, renewable energy.

\section{NOMENCLATURE}

Indices and sets

$\begin{array}{ll}k & \text { Index of scheduling time } \\ n & \text { Index of electrolysis cell branch } \\ \Delta k & \text { Time interval }\end{array}$

\section{Parameters}

$a_{1}, a_{2}, a_{3}, a_{4}$

$C_{\mathrm{z}, n}, C_{\mathrm{W}, n}$

Coefficients of battery cycle life

Thermal capacitances of electrolyte and wall $\left(\mathrm{kWh} /{ }^{\circ} \mathrm{C}\right)$

$D L_{e, k, \max }, D L_{h, k, \max }$ Maximum limits of interruptible loads for electricity and heat $(\mathrm{kW})$

$d_{\mathrm{hZ}, n}, d_{\mathrm{hW}, n} \quad$ Geometric characteristic length of heat trans-

$E_{\mathrm{R}}$ fer surface of electrolyte and wall (m)

$F$ Energy storage capacity of battery $(\mathrm{kWh})$

$f_{\mathrm{A}, \mathrm{ramp}, n}, f_{\mathrm{A}, \max , \mathrm{n}}$ Faraday constant $(\mathrm{C} / \mathrm{mol})$

Ramp rate and maximum production of electrolysis cells per time interval $\left(\mathrm{m}^{3}\right)$

This work was jointly supported by the National Natural Science Foundation of China (51877072) and Huxiang Young Talents Programme of Hunan Province under Grant 2019RS2018. (Corresponding author: Bin Zhou)

D. Xu, B. Zhou, C. Li, and S. Chen are with the College of Electrical and Information Engineering, Hunan University, Changsha 410082, China, and also with the Hunan Key Laboratory of Intelligent Information Analysis and Integrated Optimization for Energy Internet, Hunan University, Changsha 410082, China (e-mail: binzhou@hnu.edu.cn).

Q. Wu and S. Huang is with the Center for Electric Power and Energy, Department of Electrical Engineering, Technical University of Denmark, Kgs. Lyngby, 2800 Denmark.

C. Y. Chung is with the Department of Electrical and Computer Engineering, University of Saskatchewan, Saskatoon, SK S7N5A9, Canada.

\begin{tabular}{|c|c|}
\hline$f_{\text {ng }}$ & $\begin{array}{l}\text { Rated production of nitrogen generator } \mathrm{p} \\
\text { time interval }\left(\mathrm{m}^{3}\right)\end{array}$ \\
\hline$h_{\mathrm{Z}, n}, h_{\mathrm{W}, n}$ & Height of electrolyte and wall (m) \\
\hline$I_{k, n}$ & Current density of electrolysis cells $\left(\mathrm{A} / \mathrm{m}^{2}\right)$ \\
\hline$L_{e O, k}, L_{h 0, k}$ & Electrical and thermal loads $(\mathrm{kW})$ \\
\hline$L_{n}$ & Cell length (m) \\
\hline$N_{\mathrm{uZ}, n}, N_{\mathrm{uW}, n}$ & Nusselt number of the electrolyte and wall \\
\hline$N_{\mathrm{c}}, N_{\mathrm{b}}$ & Number of electrolysis cells and branches \\
\hline$N_{\mathrm{e}}$ & Number of electrons transferred in the reaction \\
\hline$P_{\mathrm{WT}, k}, P_{\mathrm{PVT}, k}, H_{\mathrm{PVT}, k}$ & $\begin{array}{l}\text { Electrical and thermal outputs of WT and } \\
\text { PVT }(\mathrm{kW})\end{array}$ \\
\hline$P_{\mathrm{ch}, \max }, P_{\mathrm{dis}, \max }$ & $\begin{array}{l}\text { Maximum charging and discharging of bat- } \\
\text { tery }(\mathrm{kW})\end{array}$ \\
\hline$P_{\mathrm{E}, n}, P_{\mathrm{ng}}$ & Electrolyzerand $\mathrm{N}_{2}$ generator rated power $(\mathrm{kW})$ \\
\hline$R_{\mathrm{z}, n}, R_{\mathrm{W}, n}, R_{\mathrm{air}, n}$ & $\begin{array}{l}\text { Thermal resistances of electrolyte, wall, and } \\
\text { electrolyte surface }\left({ }^{\circ} \mathrm{C} / \mathrm{kW}\right)\end{array}$ \\
\hline$r_{i, n}$ & Slope of the $i$ th piece of efficiency curve \\
\hline $\begin{array}{l}S_{\mathrm{B}, \max }, S_{\mathrm{CHP}, \max } \\
S_{\mathrm{F}, \max }\end{array}$ & $\begin{array}{l}\text { Maximum outputs of electric boiler, } \mathrm{CH} \\
\text { and furnace }(\mathrm{kW})\end{array}$ \\
\hline $\begin{array}{l}S O C_{\mathrm{BES}, \min } \\
S O C_{\mathrm{BES}, \max }\end{array}$ & $\begin{array}{l}\text { Minimum and maximum values of battery } \\
\text { SOC }\end{array}$ \\
\hline$S O C_{\mathrm{BES}, \mathrm{ref}}$ & Reference SOC of battery \\
\hline$S O C_{\mathrm{A}, \min }, S O C_{\mathrm{A}, \max }$ & Lower and upper SOC values of $\mathrm{NH}_{3}$ tank \\
\hline$T_{i}$ & Break-point of $i$ th piece of efficiency curve \\
\hline$T_{Z, \min }, T_{Z, \max }$ & Lower and upper reaction temperature $\left({ }^{\circ} \mathrm{C}\right)$ \\
\hline$T_{\text {out }, k}$ & Temperature of electrolyzer outside $\left({ }^{\circ} \mathrm{C}\right)$ \\
\hline$V_{\mathrm{GS}, \min }, V_{\mathrm{GS}, \max }$ & Minimumandmaximum $\mathrm{NH}_{3}$ tankoutputs $\left(\mathrm{m}^{3}\right)$ \\
\hline$V_{\mathrm{R}}$ & Rated capacity of $\mathrm{NH}_{3}$ storage $\left(\mathrm{m}^{3}\right)$ \\
\hline$W_{n}$ & Cell width (m) \\
\hline$\lambda_{\mathrm{Z}, n,} \lambda_{\mathrm{W}, n}$ & $\begin{array}{l}\text { ictivity of the electrolyte and } \\
\text { yzer }\left(\mathrm{W} /\left(\mathrm{m} .{ }^{\circ} \mathrm{C}\right)\right)\end{array}$ \\
\hline$\lambda_{\text {air }, n}$ & $\begin{array}{l}\text { Convective heat transfer coefficient of elec- } \\
\text { trolyte surface }\left(\mathrm{W} /\left(\mathrm{m}^{2} \cdot{ }^{\circ} \mathrm{C}\right)\right)\end{array}$ \\
\hline$Q_{\text {gas }}$ & Enthalpy change of the reaction $\left(\mathrm{kWh} / \mathrm{m}^{3}\right)$ \\
\hline $\begin{array}{l}\eta_{B}, \eta_{e, \mathrm{CHP}}, \eta_{h, \mathrm{CHP}} \\
\eta_{\mathrm{F}}\end{array}$ & $\begin{array}{l}\text { Energy conversion efficiencies of boiler, } \\
\mathrm{CHP} \text {, and furnace }\end{array}$ \\
\hline$\mu_{\mathrm{E}, n}$ & Capital cost of electrolysis cells $(\$ / \mathrm{kW})$ \\
\hline$r_{\mathrm{E}, n}$ & Lifetime of electrolysis cells (h) \\
\hline$\mu_{n g}$ & Capital cost of filter cartridges (\$/unit) \\
\hline $\mathrm{r}_{n g}$ & Lifetime of filter cartridges $(\mathrm{h})$ \\
\hline$\mu_{\mathrm{ESU}, n}, \mu_{\mathrm{ESD}, n}$ & $\begin{array}{l}\text { Unit degradation cost caused by startup and } \\
\text { shutdown of electrolysis cells (\$/on, \$/off) }\end{array}$ \\
\hline$\mu_{\mathrm{BES}}$ & Capital cost of battery $(\$ / \mathrm{kWh})$ \\
\hline$r_{\mathrm{BES}}$ & Estimated cycle life of battery (cycles) \\
\hline$\mu_{\mathrm{P}}$ & Unit cost of load shedding $(\$ / \mathrm{kWh})$ \\
\hline
\end{tabular}

$f_{\mathrm{ng}}$

$h_{\mathrm{Z}, n}, h_{\mathrm{W}, n}$

$L_{n}$

$N_{n}, N_{\mathrm{uW}}$

$P_{\mathrm{ch}, \max }, P_{\mathrm{dis}, \max }$

$P_{\mathrm{E}, n}, P_{\mathrm{ng}}$

$r_{i, n}$

$S_{\mathrm{B}, \max }, S_{\mathrm{CHP}, \max }$,

$S_{\mathrm{F}, \max }$

$S O C_{\mathrm{BES}, \min }$

$S O C_{\mathrm{BES} \text {,ref }}$ L

$$
T_{i}
$$

$T_{\mathrm{Z}, \min }, T_{\mathrm{Z}, \max }$

$T_{\text {out }, k}$

\section{$V_{\mathrm{R}}$}


$\eta_{\mathrm{ch}}, \eta_{\mathrm{dis}} \quad$ Battery charging and discharging efficiency

\begin{tabular}{|c|c|}
\hline riables & \\
\hline $\mathrm{C}_{T C, k}$ & System operating cost $(\$)$ \\
\hline $\mathrm{C}_{B C, k}$ & Battery degradation cost $(\$)$ \\
\hline $\mathrm{C}_{L C, k}$ & Load shedding cost $(\$)$ \\
\hline $\mathrm{C}_{D C, k}$ & P2A degradation cost $(\$)$ \\
\hline $\mathrm{C}_{E D C, k}$ & Electrolyzer degradation cost $(\$)$ \\
\hline $\mathrm{C}_{n g, k}$ & $\mathrm{~N}_{2}$ generator degradation cost $(\$)$ \\
\hline$D L_{e, k}, D L_{h, k}$ & Amounts of multi-energy load shedding $(\mathrm{kW})$ \\
\hline$f_{\mathrm{A}, k, n}$ & $\mathrm{NH}_{3}$ production per time interval $\left(\mathrm{m}^{3}\right)$ \\
\hline$L_{e, k}, L_{h, k}$ & Supplied electrical and thermal loads $(\mathrm{kW})$ \\
\hline$n_{\mathrm{b}, k}$ & Number of operating electrolysis cell branch \\
\hline$P_{\mathrm{BES}, k}, V_{\mathrm{GS}, k}$ & $\begin{array}{l}\text { Net output of battery and } \mathrm{NH}_{3} \text { tank, i.e., dis- } \\
\text { charging minus charging }\left(\mathrm{kW}, \mathrm{m}^{3}\right)\end{array}$ \\
\hline$P_{\mathrm{dis}, k}, P_{\mathrm{ch}, k}$ & Battery discharging and charging power (kW) \\
\hline$Q_{\mathrm{RES}, k, n}$ & Joule heating from RESs $(\mathrm{kW})$ \\
\hline$S_{\mathrm{ef}, k}, S_{\mathrm{hf}, k}$ & Electricity and heat for reaction heating $(\mathrm{kW})$ \\
\hline$S_{\mathrm{E}, k, n}$ & Electricity consumption of electrolyzer $(\mathrm{kW})$ \\
\hline$S_{\mathrm{ng}, k}$ & Electricity consumption of $\mathrm{N}_{2}$ generator $(\mathrm{kW})$ \\
\hline$S_{\mathrm{B}, k}, S_{\mathrm{CHP}, k}, S_{\mathrm{F}, k}$ & Outputs of boiler, CHP, and furnace $(\mathrm{kW})$ \\
\hline$S O C_{\mathrm{BES}, k}, S O C_{\mathrm{A}, k}$ & SOC of battery and $\mathrm{NH}_{3}$ storage \\
\hline$T_{\mathrm{Z}, k, n}, T_{\mathrm{W}, k, n}$ & Temperatures of electrolyzer and wall $\left({ }^{\circ} \mathrm{C}\right)$ \\
\hline$U_{k, n}$ & Cell voltage $(\mathrm{V})$ \\
\hline$V_{\mathrm{m}, k, n}$ & Molar volume $\left(\mathrm{m}^{3} / \mathrm{mol}\right)$ \\
\hline$\omega_{k, n}$ & $\begin{array}{l}\text { Binary variable that registers the on/off state } \\
\text { of electrolysis cell branch }\end{array}$ \\
\hline$\eta_{\mathrm{A}, k}$ & Electrolytic efficiency of the $\mathrm{P} 2 \mathrm{~A}$ process \\
\hline $\begin{array}{l}v_{\mathrm{B}, k}, v_{\mathrm{CHP}, k}, v_{\mathrm{F}, k} \\
v_{\mathrm{e}, k}, v_{\mathrm{h}, k}\end{array}$ & $\begin{array}{l}\text { Dispatch factors of input flows splitted up to } \\
\text { boiler, CHP, furnace, electrical and heat loads }\end{array}$ \\
\hline$\eta_{\mathrm{F}, k}$ & Faradaic efficiency of the P2A process \\
\hline
\end{tabular}

\section{INTRODUCTION}

$\mathrm{W}$ ORLD'S installed capacity of renewable energy sources (RESs) is estimated to be continually increasing in this century due to the worldwide consensus of pursuing a lowcarbon and clean energy system [1],[2]. Achieving such a high penetration of renewables undoubtedly requires considerable operational flexibility to hedge their inherent intermittency and undispatchability. Energy storage systems, especially batteries, are these often-characterized "need" to mitigate the fluctuations, and extensive efforts in [3]-[7] have designed various batteryintegrated hybrid energy systems. Nevertheless, system operators are running into the dilemma of operational economy and reliability since the frequent short-term charging and discharging actions of high-cost battery would considerably deteriorate its long-term lifetime [4],[5]. Power-to-gas (P2G) technology is another innovative controllable renewable energy storage approach and has been developed as an increasingly popular solution to cope with inherent intermittency of variable RESs [8],[9] The $\mathrm{P} 2 \mathrm{G}$ converts excess power into gaseous energy carriers by rapid response electrolysis, e.g. methane $\left(\mathrm{CH}_{4}\right)$, hydrogen $\left(\mathrm{H}_{2}\right)$ [9], which could further be stored in the equipped gas storage tank, or subsequently injected into the gas network at a later time for low-carbon heating and electrical generations. The vast bulk of countries in world, especially in Europe, have shown broader interests in this technology, and built several pilot and demonstration plants. In this context, the P2G technology offers an effective and reliable solution to facilitate high-penetrated renewable energy integration and utilization, thereby accelerating today's energy system transition.

Power-to-ammonia (P2A) is an emerging technology to react $\mathrm{H}_{2}$ from the renewable-powered electrolysis of water and nitrogen $\left(\mathrm{N}_{2}\right)$ from air separation to produce ammonia $\left(\mathrm{NH}_{3}\right)$ [10],[11]. Compared with other P2G technologies, P2A can be linked to numerous merits: 1) Due to its low volumetric energy density at ambient temperature and pressure, bulk gas storage of $\mathrm{CH}_{4} / \mathrm{H}_{2}$ requires additional energy-intensive liquefaction/compression processes and special costly storage tanks, which further increase the energy storage cost. $\mathrm{NH}_{3}$ is a renewable fuel which can be more easily and densely liquefied or transported than other gaseous carriers [10]; 2) $\mathrm{NH}_{3}$ can serve as a superior chemical storage medium and has the highest potential for large-scale storage of excess RESs, because of high round-trip efficiency, energy density, transportability, and low cost of $\mathrm{N}_{2}$ sources [12]; 3) As one of the most commonly produced chemical commodity, the industrial community has provided large amount of experiences outside the electrical community with the storage safety of $\mathrm{NH}_{3}$ [11]. These advantages make P2A significantly more appropriate for energy storage, and characteristic parameters of P2G technologies in [10],[11], such as technology readiness level (TRL), power to power efficiency (P2P), etc., are summarized in Table I. All in all, P2A has the promising potential to offer additional firm capacity, flexibility, and dispatchability for energy systems, which could serve as an ideal candidate for supporting substantial deployment of RESs and helping accelerate energy transition towards high renewables. Consequently, this paper aims to investigate the enhanced utilization of P2A to deal with the variability of RESs, and provide cost-effective multi-energy services.

TABLE I

COMPARISON OF P2A As ENERGy STORAGE WITH ALternatives [10],[11]

\begin{tabular}{cccccc}
\hline \hline P2G & $\begin{array}{c}\text { Energy den- } \\
\text { sity }(\text { Wh.L-1 })\end{array}$ & $\begin{array}{c}\text { Heating value } \\
(\mathrm{KJ} / \mathrm{mol})\end{array}$ & $\begin{array}{c}\text { P2P } \\
(\%)\end{array}$ & TRL & Storage Safety \\
\hline $\mathrm{NH}_{3}$ & 4325 & 382.6 & 39 & $4-7$ & $\begin{array}{c}\text { Toxity, much indus- } \\
\text { trial experience }\end{array}$ \\
$\mathrm{CH}_{4}$ & 6400 & 889 & 28 & 9 & $\begin{array}{c}\text { Explosive, cryogenic } \\
\text { Explosive, cryogenic }\end{array}$ \\
$\mathrm{H}_{2}$ & 2600 & 286 & 34 & $6-8$ &
\end{tabular}

So far, the P2A was generally carried out based on the energy- and capital-intensive Haber-Bosch process under harsh conditions, and however its $\mathrm{NH}_{3}$ yield is very low due to the unfavorable chemical equilibrium [10],[11]. Further studies on photoelectrocatalytic and electrocatalytic $\mathrm{N}_{2}$ reduction reaction under ambient temperature and pressure were investigated in [13],[14], and these catalysts endowed the electrochemical reaction with a high $\mathrm{NH}_{3}$ production and low activation energy under mild conditions. Furthermore, various renewables, including wind, solar, hydro, tidal energy etc., have been incorporated with the P2A in [10]-[12],[15]-[18] and studied from various perspectives, such as process modeling and simulation, technical and economic analysis, feasibility analysis for value chains and business cases. Also, P2A-integrated hybrid energy systems were reported in [12],[19] for combined power and heat generations, and the system operational energy and exergy efficiencies are further analyzed. However, the effective utilization of interactive couplings and dispatchability between P2A and multi-energy carriers to facilitate the integration of fluctuating RESs are not involved yet.

In this paper, the $\mathrm{P} 2 \mathrm{~A}$ is proposed to form a coupled multi- 
carrier energy supply framework for high renewable penetrated energy systems. The key contributions of research are threefold:

1) A thermodynamic model of electrolyzer is mathematically formulated to investigate multi-energy coupling mechanisms among P2A and RESs based on thermo-electrochemical effects. Compared with previous $\mathrm{P} 2 \mathrm{G}$ technologies with uncontrollable electrolytic temperature or efficiency, such model allows control of thermodynamic behaviours of electrolyzer under intermittent renewable energy feedback and assists in the optimization of its steady-state performance for $\mathrm{NH}_{3}$ yield enhancement.

2) A generalized $\mathrm{P} 2 \mathrm{~A}$ degradation cost model is proposed to incorporate the long-term capital cost and lifetime into the short-term degradation process. This model systematically integrates the daily operational and commuted life-cycle degradation of nitrogen generator and electrolyzer, which could provide a quantitative cost-benefit analysis for the efficient coordination with battery and P2A storage.

3) The enhanced utilization of $\mathrm{N}_{2}-\mathrm{NH}_{3}$ cycles is proposed to form a renewable energy hub in order to analyze and exploit its potential benefits in multi-energy supplies with hybrid renewables, and the optimal multi-energy utilization problem is further decomposed into computationally tractable subproblems that are solved with efficient off-the-shelf solvers in a distributed way.

\section{P2A MODELING}

$\mathrm{P} 2 \mathrm{~A}$ refers to the process of producing synthetic $\mathrm{NH}_{3}$, and the whole formula in aqueous solution can be represented by $6 \mathrm{H}_{2} \mathrm{O}+2 \mathrm{~N}_{2} \rightarrow 4 \mathrm{NH}_{3}+3 \mathrm{O}_{2}$ in an electrolyzer driven by RESs. The preferential mechanism and reaction pathway of heterogeneous P2A processes depend strongly on the type/material of catalysts and electron structure of active surfaces [14]. Heterogeneous catalysts, including metal and non-metal electrocatalysts have thus been investigate in [13] to function at electrode surfaces or as the electrode surface itself for accelerating the P2A electrochemical reaction rate. The $\mathrm{pH}$ value also has an effect on $\mathrm{NH}_{3}$ production. Various alkaline, acidic, and neutral electrolytes, including dilute $\mathrm{H}_{2} \mathrm{SO}_{4}, \mathrm{Na}_{2} \mathrm{SO}_{4}, \mathrm{KOH}, \mathrm{HCl}, \mathrm{KHCO}_{3}$ aqueous solutions, etc., have been introduced to adjust the $\mathrm{pH}$ value of electrolyte. Here, electrochemical cells based on a mixed $\mathrm{NH}_{4}{ }^{+} / \mathrm{H}^{+}$conducting electrolyte and $\mathrm{Pt} / \mathrm{C}$ electrodes are adopted in this work due to its high $\mathrm{NH}_{3}$ yield under the room temperature and atmospheric pressure. While $\mathrm{H}_{2} \mathrm{O}$ will be decomposed into $\mathrm{O}_{2}$ according to the reaction $2 \mathrm{H}_{2} \mathrm{O} \rightarrow \mathrm{O}_{2}+4 \mathrm{H}^{+}+4 \mathrm{e}^{-}$at the anode, $\mathrm{H}^{+}$will be transferred through the Nafion membrane to the react with $\mathrm{N}_{2}$ to form $\mathrm{NH}_{3}$ according to the reaction $\mathrm{N}_{2}+6 \mathrm{H}^{+}+6 \mathrm{e}^{-} \rightarrow 2 \mathrm{NH}_{3} .+3 \mathrm{O}_{2}$ at the cathode. Several repeating electrolysis cells are assembled in the center of a large stack to guarantee an adequate $\mathrm{NH}_{3}$ production rate [20]. Without loss of generality, a certain number of electrolysis cells will be electrically connected in series to form a branch, which will then be connected in parallel to form the whole electrolyzer module. The ideal gas behavior is applied to all gas streams where appropriate [21].

\section{A. Ammonia production modeling}

According to Faraday's law, the $\mathrm{NH}_{3}$ yield is theoretically approximately proportional to the current density. However, due to the effects of operational current densities, temperature, and pressure on parasitic current and cross permeation, it is required to be incorporated with the Faradaic efficiency when applying onto the electrolysis cell. Faradaic efficiency, also known as current efficiency, describes the efficiency with which $N_{\mathrm{e}}$ electrons are transferred in a system facilitating an electrochemical reaction [20]. Faradaic efficiency of the P2A process $\eta_{\mathrm{F}, k}$ is measured by bulk electrolysis with cells where a known quantity of $\mathrm{H}_{2} \mathrm{O}$ and $\mathrm{N}_{2}$ is stoichiometrically converted to product $\mathrm{NH}_{3}$ as measured by the current $I_{k, n}$ passed. For the mixed connection modules with a number $N_{\mathrm{c}}$ of series-wound electrolysis cells and a number $N_{\mathrm{b}}$ of shunt-wound electrolysis cell branches, the total $\mathrm{NH}_{3}$ production $f_{\mathrm{A}, k, n}$ can be modeled as:

$$
\begin{gathered}
f_{\mathrm{A}, k, n}=\frac{N_{c \quad \mathrm{~F}, k} V_{\mathrm{m}, k, n} I_{k, n} k}{N_{e} F} \\
f_{\mathrm{A}, k}={ }_{1}^{N_{b}} f_{\mathrm{A}, k, n}
\end{gathered}
$$

where $V_{\mathrm{m}, k, n}$ is the molar volume of electrolysis cell branch $n$ at corresponding reaction temperature and pressure. Since pressurized operation has only a negligible effect on electrolyzer performance [22], the operating pressure is approximately regarded as constant here, and $V_{\mathrm{m}, k, n}$ would be directly proportional to the temperature according to the isobaric ideal gas law $P V=N R T$ :

$$
\frac{V_{\mathrm{m}, k, n}}{T_{\mathrm{Z}, k}}=\frac{V_{\mathrm{m}, k, n}^{\prime}}{T_{\mathrm{Z}, k}^{\prime}}=\mathrm{constant}
$$

According to the definition of electrolytic efficiency $\eta_{\mathrm{A}, k}$, the electrical consumption of electrolyzer $S_{\mathrm{E}, k, n}$ can be calculated as:

$$
\begin{gathered}
S_{E, k, n}=\frac{f_{\mathrm{A}, k, n} Q_{\text {gas }}}{{ }_{\mathrm{A}, k} k} \\
S_{E, k}={ }_{1}^{N_{b}} S_{E, k, n}
\end{gathered}
$$

where $S_{\mathrm{E}, k, n}$ is equal to the product of $U_{k, n}$ and $I_{k, n}$. The cell potential $U_{k, n}$ includes the reversible cell voltage, ohmic losses, activation overvoltages, and concentration overvoltages [22]. These irreversible overvoltages/losses would produce internal heat within the cell, whose amounts are equal to the heat consumption of the electrochemical reaction. Noted that, as for the involved low-temperature electrolysis in this study, higher heating value $Q_{\mathrm{gas}}$ is adopted to calculate the electrolytic efficiency as it refers to enthalpy change for the reaction at standard conditions from liquid $\mathrm{H}_{2} \mathrm{O}$ to gaseous $\mathrm{NH}_{3}$.

While the liquid $\mathrm{H}_{2} \mathrm{O}$ is abundant, the supplied $\mathrm{N}_{2}$ gas for reaction has to be separated from air. Pressure swing adsorption (PSA) technology has been widely applied in nitrogen generators and recognized as the first choice today for the recovery of high-purity $\mathrm{N}_{2}$, due to its high efficiency, low cost, and long lifetime [23]. The net cost of $\mathrm{N}_{2}$ produced by nitrogen generators is significantly less than the cost of bottled or liquefied nitrogen. The output of nitrogen generator generally can be adjusted to follow the gas consumption of electrolyzer, and the electrical consumption of a nitrogen generator $S_{\mathrm{ng}, k}$ can be calculated as a linear function of producing $\mathrm{N}_{2}$ :

$$
S_{n g, k}=0.5 f_{\mathrm{A}, k} P_{n g} / f_{n g}
$$

where 1 mol $\mathrm{N}_{2}$ have $2 \mathrm{~mol}$ nitrogen atoms or $2 \mathrm{~mol} \mathrm{NH}_{3}$, and thus the produced $\mathrm{N}_{2}$ is equal to $0.5 f_{\mathrm{A}, k, n}$.

Temperature is an important factor influencing the chemical reaction rates and courses [24]. The efficiencies increase with the increase of reaction temperature since more thermal energy is available to reach the necessary activation energy for breaking bonds between atoms. Using the piecewise linear method to fit measured data [13],[24], the $\eta_{A, k}$ and $\eta_{F, k}$ can be modeled as: 


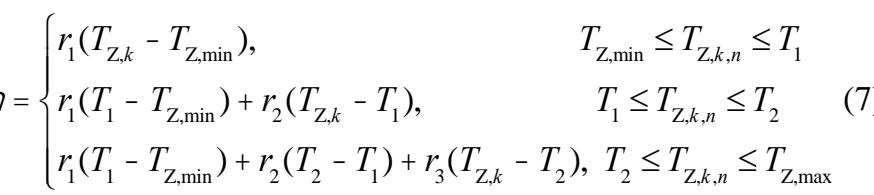

\section{B. Thermo-electrochemical modeling}

A thermodynamic model is formulated to analyze the thermoelectrochemical effects under external injection from renewable energy. The schematic diagram of physical electrolysis device is shown in Fig. 1(a). The P2A physical electrolysis climate is composed of surrounding walls, reaction zone, and the outside air, which can store and transfer thermal energy between each other in different ways. The whole climate is affected by all heat change inside this area, including the external heating from renewables, enthalpy change of the $\mathrm{P} 2 \mathrm{~A}$ reaction on the cathode/electrolyte and anode/electrolyte interface, etc. Such heat storage capacity and heat transmissibility of electrolyzer elements are generally denoted by means of thermal resistance and capacitance to express their essential thermal properties [7]. Here, the temperature, heat storage, and heat transfer properties of electrolysis zones and surrounding walls are handled with the classical lumped parameter method by defining equivalent thermal resistors, capacitors, and masses at their geometric center. The heat change inside this area is assumed to all take place on these central nodes. A resistor-capacitor thermal circuit can then be derived to model the temperature dynamics of the P2A physical electrolysis climate, as shown in Fig.1(b). The structure and material properties of electrolyzer at all directions are regarded as the same and constant, and their thermodynamic parameters can thus be further computed as spatial averages along the electrolysis cells so as to form a computationally tractable steady-state model of electrolysis.

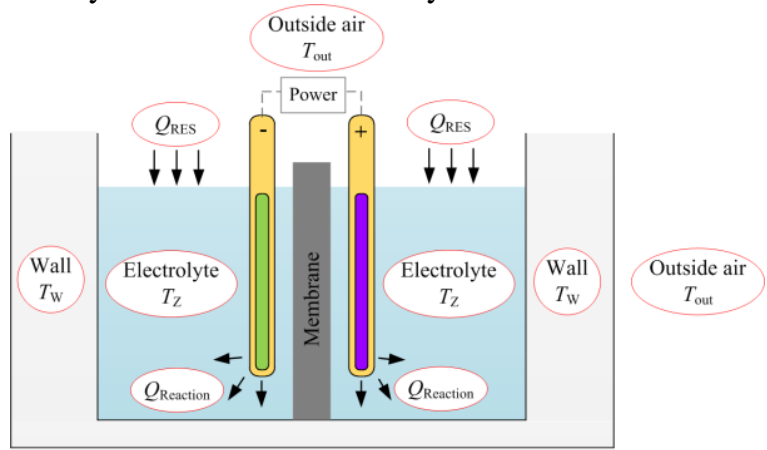

(a) Schematic diagram of physical electrolysis device

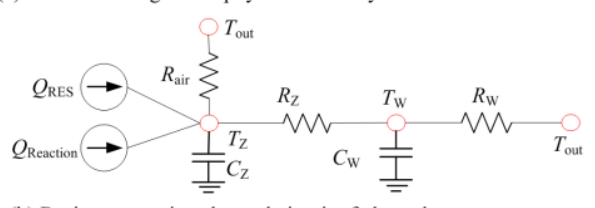

(b) Resistor-capacitor thermal circuit of electrolyzer

Fig. 1 P2A physical electrolysis device and its thermal circuit

The temperatures of its inside reaction zone, wall, and outside $T_{\mathrm{Z}, k, n}, T_{\mathrm{W}, k, n}, T_{\text {out }, k}$ are denoted by nodes with thermal capacitances $C_{z, n}, C_{\mathrm{W}, n}$. The wall node is connected with the inside and outside nodes via thermal resistances $R_{\mathrm{z}, n}, R_{\mathrm{W}, n}, R_{\mathrm{air}, n}$ to represent external and internal convective/conductive heat transfer. Given the laminar flow conditions [21], the thermal resistances can be calculated using a constant Nusselt number $N_{\mathrm{uZ}, n}, N_{\mathrm{uW}, n}$, characteristic length $d_{\mathrm{hZ}, n}, d_{\mathrm{hW}, n}$, and their thermal conductivity $\lambda_{\mathrm{Z}, n,}, \lambda_{\mathrm{W}, n}, \lambda_{\mathrm{air}, n}$ of the inside electrolyte, wall, and air, as follows:

$$
\begin{array}{r}
R_{\mathrm{Z}, n}=\frac{d_{\mathrm{h}, \mathrm{Z}, n}}{N_{u Z, n} \quad \mathrm{Z}, n} \\
R_{\mathrm{W}, n}=\frac{d_{\mathrm{h}, \mathrm{W}, n}}{N_{u W, n \quad \mathrm{~W}, n}} \\
R_{\mathrm{air}, n}=\frac{1}{W_{n} L_{n} \text { air }, n}
\end{array}
$$

where the characteristic length $d_{\mathrm{hZ}, n}, d_{\mathrm{hW}, n}$ of the electrolyte and wall are calculated as:

$$
\begin{gathered}
d_{\mathrm{h}, \mathrm{Z}, n}=\frac{2 W_{n} h_{Z}}{W_{n}+h_{Z}} \\
d_{\mathrm{h}, \mathrm{W}, n}=\frac{2 W_{n} h_{W}}{W_{n}+h_{W}}
\end{gathered}
$$

Then, the thermal dynamics are governed by Fourier's law:

$$
\begin{gathered}
C_{\mathrm{Z}, n} \frac{d T_{\mathrm{Z}, k, n}}{d k}=\frac{T_{\mathrm{W}, k, n} T_{\mathrm{Z}, k, n}}{R_{\mathrm{Z}, n}} \frac{T_{\mathrm{Z}, k, n} T_{\mathrm{out}, k, n}}{R_{\mathrm{air}, n}}+Q_{\mathrm{RES}, k, n} \\
+S_{E, k, n} k \quad f_{\mathrm{A}, k, n} Q_{\mathrm{gas}} \\
C_{\mathrm{W}, n} \frac{d T_{\mathrm{W}, k, n}}{d k}=\frac{T_{\mathrm{Z}, k, n}-T_{\mathrm{W}, k, n}}{R_{\mathrm{Z}, n}}+\frac{T_{\text {out }, k}-T_{\mathrm{W}, k, n}}{R_{\mathrm{W}, n}} \\
Q_{\mathrm{RES}, k, n}={ }_{\mathrm{B}} S_{\mathrm{ef}, k, n} k+S_{\mathrm{hf}, k, n} k
\end{gathered}
$$

Here, the thermodynamic model (13)-(15) indicates the thermal interactions for heat transfer among the inside reaction zone, wall, and outside ambient environment of the electrolyzer. The left hand of (13)-(14) represent the heat change of the inside electrolyte and wall. The first two terms on the right hand of (13)-(14) represent the heat flow from the surroundings due to the temperature differences. The last four terms on the righthand side of (13) represent convective heat transfer of electrolyte surface, Joule heating from RESs, enthalpy change of the P2A endothermic reaction, and Joule heating from local current density. (15) represents the available renewable electrical and thermal energy harvested for $\mathrm{P} 2 \mathrm{~A}$ reaction heating. Consequently, from the thermo-electrochemical dynamics model in (1)-(15), the gain in $\mathrm{NH}_{3}$ yield resulted from hybrid solar-wind energy injections for P2A heating can further be analyzed.

\section{Modeling of $P 2 A$ degradation cost}

The P2A storage system is generally composed of a nitrogen generator, an electrolyzer, and a $\mathrm{NH}_{3}$ storage tank. The storage capacity and supply-side flexibility of P2A storage system can be used to buffer the fluctuations from renewable generations and multi-energy demands. Typically, the P2A storage system operate at their given working set-points for the whole scheduling period. However, the daily operation and on/off cycling of this P2A system would considerably degrade its service lifetime, and further affect the scheduling performance. Here, the degradations are mainly from the electrolyzer and nitrogen generator, which are further explicitly modeled to reflect their cost properties for the short-term operation. The electrolyzer and nitrogen generator have the potential to minimize the number of operational hours and on/off times under different operating conditions.

A PSA nitrogen generator uses a carbon molecular sieve (CMS) to adsorb $\mathrm{O}_{2}$ under high pressure while allowing the $\mathrm{N}_{2}$ to pass through for collection in a storage unit [23]. An on-site PSA nitrogen generator have only a few moving parts and if properly maintained can last for many years. Generally, an on- 
site PSA nitrogen generator can maintain its performance for over twenty years. Pellets that form the hub of the PSA gas filtering process (Zeolite or CMS) have an extensive lifespan and can also last for at least for decades. With clean and dry feed air most of the annual maintenance is simply changes filter cartridges. Therefore, the degradation cost of a nitrogen generator can be modeled as a cost function of filter cartridges:

$$
C_{n g, k}=k_{n g} \max \left({ }_{k, n}\right) / r_{n g}
$$

where the producing/recycling cost of nitrogen only exists as long as the nitrogen generator/electrolyzer is turned on.

Electrolyzer is characterized by low capital cost, ability to scale up, long durability, which is capable of achieving a much longer lifetime and not suffered from cycling issues. The electrolyzer has different degradation mechanisms with battery. While frequent and deep charging/discharging actions and ambient temperature would cause considerable degradation to battery, it has been extensively shown that degradation of electrolyzer lifetime and stack performance occurs much quicker under impacts of rapid current fluctuations, on/off cycling and operation close to open cell voltage [25]. Operation at too high/low or highly fluctuating current/voltage for a long time would cause mechanical wear of the membrane and chemical degradation of the membrane. The on/off cycling of electrolyzer is also more likely to accelerate stack degradation, leading to operating efficiency loss and cycle count decrease. However, such degradations over short-term horizons could be negligible once its voltage/current is enforced within the proper ranges, so as for other external parameters including temperature and pressure. Since the electrolyzer lifetime as well as its recommended working temperature and current/voltage would be indicated by manufacturing specifications, electrolyzer is in general expected to be operated under recommended normal/mild conditions to last for the estimated life. Therefore, the electrolyzer degradation cost can be modeled as follows:

$$
\begin{aligned}
C_{E D C, k, n}= & k_{E, n \quad k, n} / r_{E, n}+{ }_{E S U, n \quad k, n}\left(\begin{array}{ll}
k 1, n \\
\end{array}\right) \\
& +E_{E S D, n} \quad k 1, n
\end{aligned}
$$

where the first term is the daily operational degradation and the last two terms are the on/off cycling degradation.

Different from the complex battery degradation cost model (which would be given in next section), the electrolyzer degradation cost only depends on operating time and on/off cycling conditions. These favorable operating properties further indicate the flexibility of electrolyzer systems and its potential as an alternative to energy storage to alleviate unnecessary discharging/charging of battery.

The electrolysis cells can start up and shut down rather quickly, and their $\mathrm{NH}_{3}$ yield is then limited by the electrolysis cell branch turned on. Also, due to physical and safety limitations, the $\mathrm{NH}_{3}$ yield $f_{\mathrm{A}, k, n}$ is limited by maximum operational level of electrolysis cells $f_{\mathrm{A}, \max , \mathrm{n}}$, as follows:

$$
0 f_{\mathrm{A}, k, n} f_{\mathrm{A}, \max , n} \quad k, n
$$

Due to endogenous inertia of liquid electrolyte and velocity limits of the cathode/anode gas streams, electrolysis cells require time to follow the power set-point change and electrochemistry change within the electrolyzer stack which further limits their ramp capability of $\mathrm{NH}_{3}$ production levels $f_{\mathrm{A}, \mathrm{ramp}, n}$ between two consecutive time slots, as follows:

$$
\left|f_{\mathrm{A}, k, n} \quad f_{\mathrm{A}, k 1, n}\right| \quad f_{\mathrm{A}, \mathrm{ramp}, n}
$$

\section{Multi-EnERgy UtilizATION WITH P2A}

\section{A. P2A driven energy hub framework}

The proposed P2A driven energy hub framework in Fig. 2 is supplied by wind and solar energies which can be converted into electrical and thermal energy by the wind turbine (WT) and photovoltaic thermal (PVT) system. Noted that the PVT system is a renewable cogeneration system, which incorporates both solar thermal collectors and photovoltaic panels [7],[26]. These energy carriers are converted and conditioned through several multi-energy converters and storages into different qualities and quantities of multi-energy loads. In this framework, the available electrical and thermal energy from wind and solar generations can be used to heat the electrolyzer, thereby facilitating the $\mathrm{P} 2 \mathrm{~A}$ reaction to increase $\mathrm{NH}_{3}$ yield. The produced $\mathrm{NH}_{3}$ is an intermediate and flexible energy carrier, which can be used as a transitional energy storage to mitigate intermittent and volatile RESs, or as a carbon-neutral fuel for combined heat and power (CHP) [7]. Both of battery and $\mathrm{NH}_{3}$ tank can offer large storage capacities for available electricity and $\mathrm{NH}_{3}$. The renewablepowered $\mathrm{P} 2 \mathrm{~A}$ electrolyzer serves as an important medium to transform $\mathrm{N}_{2}$ into $\mathrm{NH}_{3}$, and the $\mathrm{N}_{2}$ from the combustion of $\mathrm{NH}_{3}$ can be in turn captured and recycled by the P2A through a PSA air separator. The $\mathrm{N}_{2}-\mathrm{NH}_{3}$ cycle offers a sustainable and effective way to heat the reaction for $\mathrm{NH}_{3}$ yield enhancement based on thermo-electrochemical effects, and also promotes the operational flexibility for multi-carrier energy supplies.

Various multi-energy storages and converters in energy hub offers opportunities to enhance renewable energy utilization and system operational economy by providing a certain degree of flexibility and synergies in energy supply. According to the converter efficiency and hub internal topology, an energy hub model is formulated in (20) which can be further used to analyze and exploit its inherent controllability and flexibility.

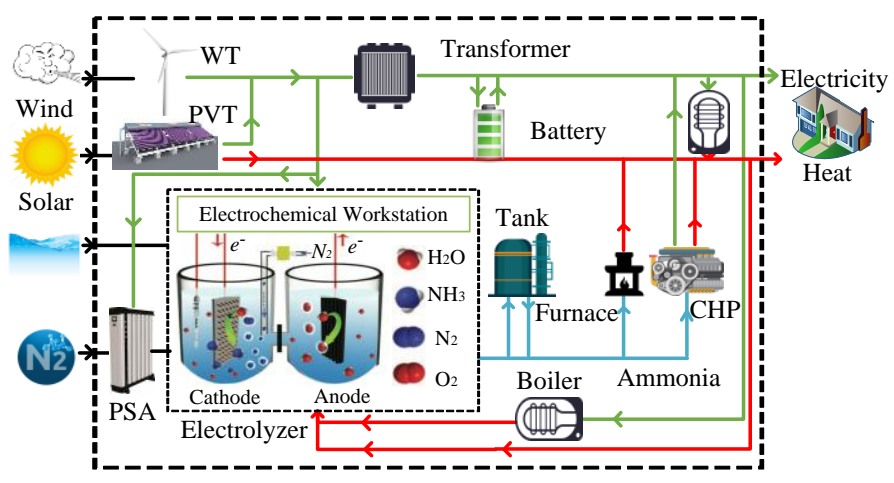

Fig. 2 P2A driven energy hub framework

\section{B. Objective function}

The objective is to minimize the system operating cost $C_{T C, k}$ in the whole scheduling process, including $\mathrm{P} 2 \mathrm{~A}$ degradation cost $\mathrm{C}_{D C, k}$, battery degradation cost caused by charging/discharging cyclings $\mathrm{C}_{B C, k}[5],[7]$, load shedding cost $\mathrm{C}_{L C, k}$ :

$$
\begin{gathered}
C_{T C, k}=C_{D C, k}+C_{B C, k}+C_{L C, k} \\
C_{D C, k}={ }_{1}^{N_{b}} C_{E D C, k, n}+C_{n g, k} \\
C_{B C, k}=\frac{\left(P_{\mathrm{ch}, k}+P_{\mathrm{dis}, k}\right)_{\mathrm{BES}} r_{\mathrm{BES}} k}{a_{1}\left[a_{2}\left(1 \quad S O C_{\mathrm{BES}, k}\right)+a_{3}\right] \exp \left(a_{4} T_{\mathrm{out}, k}\right)\left(1 \quad S O C_{\mathrm{BES}, \mathrm{ref}}\right)}
\end{gathered}
$$




$$
\left[\begin{array}{c}
L_{e, k} \\
L_{h, k}
\end{array}\right]=\underbrace{\left[\begin{array}{llllll}
v_{e, k} & v_{e, k} & 0 & Q_{\mathrm{gas}} v_{\mathrm{CHP}, k} \eta_{e, \mathrm{CHP}} v_{e, k} / \Delta k & v_{e, k} & Q_{\mathrm{gas}} v_{\mathrm{CHP}, k} \eta_{e, \mathrm{CHP}} v_{e, k} / \Delta k \\
v_{\mathrm{B}, k} \eta_{\mathrm{B}} v_{h, k} & v_{\mathrm{B}, k} \eta_{\mathrm{B}} v_{h, k} & v_{h, k} & Q_{\mathrm{gas}}\left(v_{\mathrm{CHP}, k} \eta_{e, \mathrm{CHP}} v_{\mathrm{B}, k} \eta_{\mathrm{B}}+v_{\mathrm{CHP}, k} \eta_{h, \mathrm{CHP}}+v_{\mathrm{F}, k} \eta_{\mathrm{F}}\right) v_{h, k} / \Delta k & v_{\mathrm{B}, k} \eta_{\mathrm{B}} v_{h, k} & Q_{\mathrm{gas}}\left(v_{\mathrm{CHP}, k} \eta_{e, \mathrm{CHP}} v_{\mathrm{B}, k} \eta_{\mathrm{B}}+v_{\mathrm{CHP}, k} \eta_{h, \mathrm{CHP}}+v_{\mathrm{F}, k} \eta_{\mathrm{F}}\right) v_{h, k} / \Delta k
\end{array}\right]}_{\mathbf{L}} \underbrace{\left[\begin{array}{l}
P_{\mathrm{WT}, k} \\
P_{\mathrm{PVT}, k} \\
H_{\mathrm{PVT}, k} \\
f_{\mathrm{A}, k} \\
P_{\mathrm{BES}, k} \\
V_{\mathrm{GS}, k}
\end{array}\right]}_{\mathbf{C}}
$$

$$
C_{L C, k}={ }_{\mathrm{P}}\left(D L_{e, k}+D L_{h, k}\right) k
$$

\section{System constraints}

The model objective (21) is subjected to (1)-(20) and the following system constraints:

1) Multi-energy Generation Constraints: Constraint (25) enforce the generation limits of CHP, boiler, and furnace.

$$
0 S_{\mathrm{i}, k} \quad S_{\mathrm{i}, \max }, i=\mathrm{CHP}, \mathrm{B}, \mathrm{F}
$$

2) Multi-energy Consumption Constraints: Constraints (26)(27) is the electrical and heat supply-demand balance; Constraints (28)-(29) limit the load shedding within its threshold.

$$
\begin{gathered}
L_{e 0, k}=L_{e, k}+D L_{e, k} \\
L_{h 0, k}=L_{h, k}+D L_{h, k} \\
D L_{e, k} \quad D L_{e, k, \max } \\
D L_{h, k} \quad D L_{h, k, \text { max }}
\end{gathered}
$$

3) Multi-energy Storage Constraints: A generalized battery model in constraints (30)-(33) in [27],[28] is adopted to enforce the limits of battery state of charge (SOC) and charging/discharging rate. It has been proved in [27],[28] that $P_{\mathrm{dis}, k} P_{\mathrm{ch}, k}=0$ always holds because of $\eta_{\mathrm{ch}} \eta_{\mathrm{dis}}<1$ for battery. Constraints (34) is the $\mathrm{NH}_{3}$ storage tank model and constraints (35)(36) enforce the limits of $\mathrm{NH}_{3}$ storage tank SOC and charging/discharging rate.

$$
\begin{gathered}
S O C_{\mathrm{BES}, k}=S O C_{\mathrm{BES}, k} \quad+\frac{{ }_{\mathrm{ch}} P_{\mathrm{ch}, k} k}{E_{\mathrm{R}}} \frac{P_{\mathrm{dis}, k} k}{{ }_{\mathrm{dis}} E_{\mathrm{R}}} \\
S O C_{\mathrm{BES}, \min } \quad S O C_{\mathrm{BES}, k} S O C_{\mathrm{BES}, \max } \\
P_{\mathrm{ch}, k} P_{\mathrm{ch, \text {max }}} \\
P_{\mathrm{dis}, k} P_{\mathrm{dis}, \max } \\
S O C_{\mathrm{A}, k}=S O C_{\mathrm{A}, k} \quad \frac{V_{\mathrm{GS}, k} k}{V_{R}} \\
S O C_{\mathrm{A}, \min } \quad S O C_{\mathrm{A}, k} \quad S O C_{\mathrm{A}, \max } \\
V_{\mathrm{GS}, \min } \leq V_{\mathrm{GS}, k} \leq V_{\mathrm{GS}, \max }
\end{gathered}
$$

\section{SOLUTION METHODOLOGY}

An abstract formulation of the proposed P2A driven energy hub model (1)-(36) can be given as follows:

$$
\begin{aligned}
& \min _{, w} F(, w) \\
& \text { s.t.(1) (15),(18) (20),(25) (36) }
\end{aligned}
$$

where the objective $F$ is the total cost in (21), including (16),(17),(22)-(24); $w$ is the vector of binary on/off variables of electrolyzer; $\chi$ is the vector of other decision variables of multienergy generation, conversion, storage, and consumption devic- es. The P2A driven model (37) is a challenging mixed-integer nonlinear programming (MINLP) optimization problem which cannot be easily solved using off-the-shelf solvers directly due to nonlinear differential dynamics, multi-energy couplings, high-dimensional integer/discrete variables, and multi-energy supply-demand. In such cases, the proposed P2A driven energy hub model will be firstly reformulated to reduce the inherent nonlinearities for computational simplification, and then iteratively solved with an iterative solution approach to converge to the optimum.

\section{A. Problem reformulation}

With respect to the nonlinear dynamics incurred by differential function in (13)-(15), a linearization method for generic nonlinear differential systems in [29] is applied to linearize the thermo-electrochemical dynamics around the nearest equilibrium point of the operating state. It has been demonstrated in [29] that this linearization would not lead to significant truncation errors because of the small electrolytic temperature range. Then, a linearized state-space form of differential equations in (13)(15) can be obtained and discretized for numerical iterations:

$$
\mathbf{T}_{k+1, n}=\mathbf{A}_{n} \mathbf{T}_{k, n}+\mathbf{B}_{n} \mathbf{u}_{k, n}
$$

where $\mathbf{T}_{k, n}=\left[T_{Z, k, n}, T_{W, k, n}\right]$ is the state vector indicating the node temperatures of electrolysis cell branch $n$ at time $k ; \mathbf{u}_{k, n}=\left[T_{\text {out }, k, n}\right.$, $\left.Q_{R E S, k, n}, Q_{\text {reaction }, k, n}\right]$ is the input vector including the ambient temperature, controllable electricity and thermal energy for reaction heating, enthalpy fluxes associated with the flow of produced $\mathrm{NH}_{3}$ of electrolysis cell branch $n$ at time $k$; $Q_{\text {reac- }}$ tion,,$n=S_{\mathrm{E}, k, n} \Delta k-f_{A, k, n} Q_{\text {gas }}$; the coefficients of matrices $\mathbf{A}_{n}$ and $\mathbf{B}_{n}$ are system state matrix and input matrix which could be calculated based on thermal resistance and capacitance parameters of electrolysis cell branch $n$.

With respect to the inherent nonlinearities introduced by dispatch factors in (20), a state variable-based approach in [7] is adopted, and the inputs of multi-energy converters as well as direct interconnections are set as state variables. For example, the $\mathrm{NH}_{3}$ inputs of $\mathrm{CHP}$ and furnace, which can be allocated in (20) by multiplying dispatch factors $v_{\mathrm{CHP}}$ and $v_{\mathrm{F}}$ with the total $\mathrm{NH}_{3}$ input, are represented by $S_{\mathrm{CHP}, k}, S_{\mathrm{F}, k}$. In such cases, $S_{\mathrm{E}, k}$, $S_{\mathrm{ng}, k}, S_{\mathrm{ef}, k}, S_{\mathrm{hf}, k}, S_{\mathrm{B}, k}, S_{\mathrm{CHP}, k}, S_{\mathrm{F}, k}$ can be set as state variables to formulate a new input vector $\mathbf{E}^{\prime}$ in (39). It should be noted that $S_{\mathrm{ef}, k}, S_{\mathrm{hf}, k}$ are equal to the sum of $S_{\mathrm{ef}, k, n}, S_{\mathrm{hf}, k, n}$ of all electrolysis cell branch. Then, an extended formulation of coupling matrix $\mathbf{C}^{\prime}$ in (39) can be derived to characterize the couplings among the multi-energy supply and demand. It can also be found that the coupling matrix in (39) is much sparser for efficient computation compared to (20), and thus can provide better scalability for integrating other carriers and devices. 


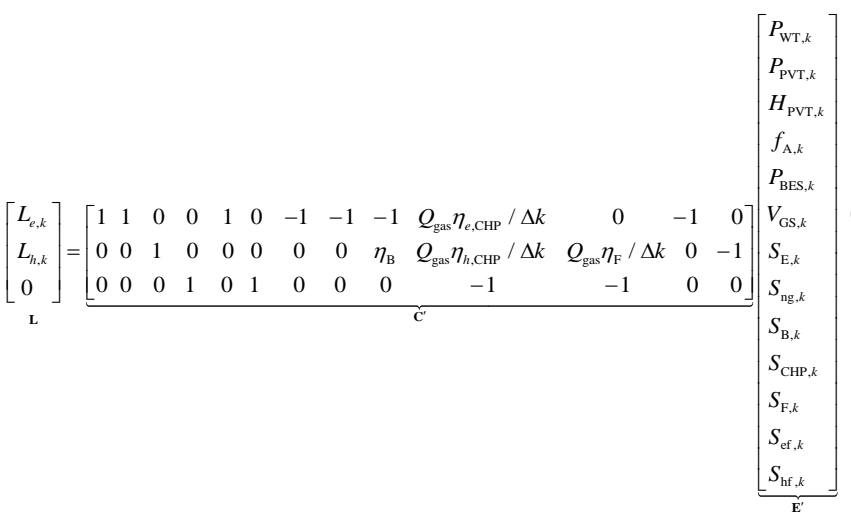

\section{B. Iterative Solution Approach}

The simplified model still contains the binary variables incurred by on/off cycling of electrolyzer in (15), which will be decomposed as a nonlinear program (NLP) subproblem and mixed-integer quadratic programming (MIQP) subproblem. The binary variable $w$ is firstly relaxed as continuous variable $c w$ within $[0,1]$, and the simplified model can then be reformulated as a relaxed NLP subproblem with the forecasting uncertainties of renewable generations captured using Monte Carlo scenarios:

$$
\begin{aligned}
& \min _{c, w}{ }_{s=1}^{S}{ }_{s}^{K}\left[C_{T C, k, s}+{ }_{1}^{N_{b}} \frac{\mathbf{d}_{w}}{2}\left\|\mathbf{w}_{k, n, s} \quad \mathbf{c w}_{k, n, s}+\mathbf{z}_{k, n, s}\right\|_{2}^{2}\right] \\
& \text { s.t.(1) (12),(18) (19),(25) (36),(38) }
\end{aligned}
$$

where the first term is operating cost over multiple periods, and the remaining terms express the consensus of binary and relaxed variables; $\mathbf{z}_{k, n}$ is the auxiliary parameter and $\mathbf{d}_{w}$ is constant step size; $\rho_{\mathrm{s}}$ is the probability of operating scenario $s$ and $S$ is the total number of scenarios. This nonconvex NLP model (40) can be easily solved using interior point method, successive quadratic programming, or any other nonlinear programming methods to obtain a locally optimal solution.

With values of continuous variables delivered from the upper subproblem (40), the following MIQP subproblem will be solved to force the continuous variable $c w$ closer and closer to the binary variable $w$ :

$$
\min _{w}{ }_{k=1}^{K} \frac{N_{b}}{2} \frac{\mathbf{d}_{w}}{2}\left\|\mathbf{w}_{k, n, s} \quad \mathbf{c w}_{k, n, s}+\mathbf{z}_{k, n, s}\right\|_{2}^{2}
$$

This subproblem (41) can be solved in a closed-form, and the optimal solution can be easily obtained as $[\mathbf{c w}]_{0}^{1}$, where $[.]_{a}^{b}$ represents the projection operator onto the binary range $[0,1]$.

The auxiliary variables are updated based on the binary variable $w$ and relaxed continuous variable $c w$ as:

$$
\mathbf{z}_{k, n, s}^{i t+1}=\mathbf{z}_{k, n, s}^{i t}+\left(\mathbf{w}_{k, n, s}^{i t} \quad \mathbf{c w}_{k, n, s}^{i t}\right)
$$

The closed-form solutions and auxiliary variables would provide a reference for the relaxed NLP subproblem where an update will be made for the next iteration. The iterations would stop when the binary and relaxed continuous variables are close enough. Algorithm 1 shows the solution process of the iterative approach.

Remark: Defining the gap between binary and relaxed continuous variables at iteration it as $r_{k, n}^{i t}=w_{k, n}^{i t}-c w_{k, n}^{i t}$, it can be found that $z_{k, n}^{i t}=z_{k, n}^{0}+\sum_{i t} r_{k, n}^{i t}$ is the running sum of the residuals, which indicates its similar and superior convergence properties in [30],[31]. It is not easy to strictly obtain the optimal solutions of the general NLP problems due to its nonconvexity properties. Nevertheless, though it is not always guaran- teed the global optimum, the approach still can provide alternative solution and satisfactory performance for the proposed P2A scheduling problems for such small-scale NLP model (40) with highly constrained feasible region.

Algorithm 1 Iterative solution approach

1: Input the parameters of renewable energy, multi-energy converters, storages, electricity and heat loads.

2: Set iteration index $i t=0$ and tolerance $\delta$; Initialize values of binary variables $\mathbf{w}$, relaxed variables $\mathbf{c w}$, and auxiliary variables $\mathbf{z}$, step sizes $\mathbf{d}$.

3: Solve the P2A driven energy hub model (40) upon receiving the latest updated binary variables $\mathbf{w}$ and auxiliary variables $\mathbf{z}$, and obtains results $\quad \mathbf{c w}$ :

$$
{ }^{i t+1}, \mathbf{c w}^{i t+1}=\underset{, c w}{\operatorname{argmin}}\left(F\left({ }^{i t}, c w^{i t}\right)\right)
$$

4: Update the binary variables $\mathbf{w}$ based on the projection of latest cw.

5: Check and verify if the relaxed continuous and binary variable are close enough:

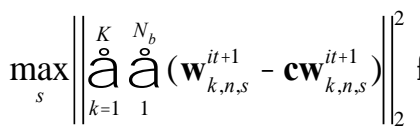

Once satisfied, the iteration ends and the final results will be output. Otherwise, the auxiliary variables $\mathbf{z}$ will be updated using (42).

6: Set $i t=i t+1$, and repeat steps 3-5 until the convergence criteria are satisfied.

\section{CASe Study}

\section{A. System Data and Configuration}

In this paper, the proposed P2A driven energy hub framework has been studied on a small-scale laboratory-level microgrid, and Fig. 2 gives the configuration of the microgrid. The installed capacities of PVT, WT, electric boilers, CHP unit, furnace, and battery are $6 \mathrm{~kW}, 10 \mathrm{~kW}, 3 \mathrm{~kW}, 5 \mathrm{~kW}, 3 \mathrm{~kW}$, and $10 \mathrm{kWh}$, respectively. The technical specifications of these converters and storage devices obtained from [5],[7],[25],[32] are given in Table II. A small-scale laboratory PSA nitrogen generator in [33] is adopted for air separation, and the characteristic parameters of electrolyzer are taken from [21],[24],[25],[34], as listed in Table II. The daily multi-energy and renewable generation profiles of microgrid are shown in Fig. 3, and their base values are set as $8 \mathrm{~kW}$. The load shedding limits $D L_{e, k, \max }$, $D L_{h, k, \max }$ are set as $20 \%$ of each type of load at the $k$ th time slot, and the unit cost of load shedding $\mu_{\mathrm{p}}$ is set as $20 \$ / \mathrm{kWh}$ [7],[35]. The scheduling strategy is implemented over 96 time slots within a day. All the tests are performed via the commercial platform GAMS [36] on a laptop with 2.3-GHz Intel Core i5 CPU and 8GB RAM, and solved with NLP solver CONOPT with their default settings.

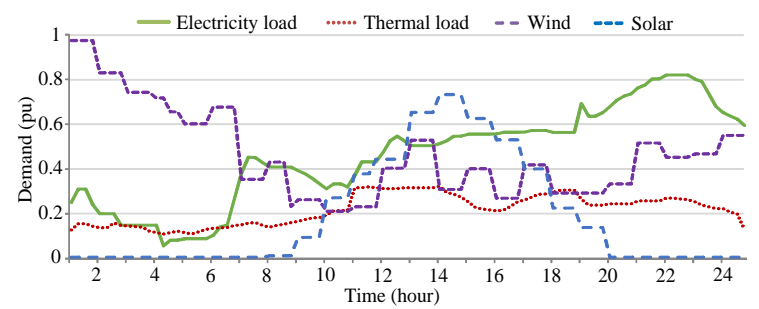

Fig. 3 Multi-energy load profiles of a small-scale microgrid 
TABLE II

TECHNICAL PARAMETERS OF MICROGRID COMPONENTS

\begin{tabular}{|c|c|c|}
\hline \multirow{15}{*}{ Electrolyzer } & $T_{Z, \min }=5^{\circ} \mathrm{C}$ & $T_{\mathrm{Z}, \max }=65^{\circ} \mathrm{C}$ \\
\hline & $F=96485 \mathrm{C} / \mathrm{mol}$ & $f_{\mathrm{A}, \mathrm{ramp}, n}=0.2 \mathrm{~m}^{3}$ \\
\hline & $f_{\mathrm{A}, \max , \mathrm{n}}=0.3 \mathrm{~m}^{3}$ & $\mathrm{I}=1000 \mathrm{~A} / \mathrm{m}^{2}$ \\
\hline & $N_{\mathrm{c}}=N_{\mathrm{e}}=3$ & $Q_{g a s}=4.339 \mathrm{kWh} / \mathrm{m}^{3}$ \\
\hline & $P_{\mathrm{E}, n}=4 \mathrm{~kW}$ & $N_{\mathrm{b}}=1$ \\
\hline & $h_{\mathrm{Z}, n}=0.5 \mathrm{~m}$ & $h_{\mathrm{W}, n}=0.01 \mathrm{~m}$ \\
\hline & $W_{n}=0.5 \mathrm{~m}$ & $L_{n}=1 \mathrm{~m}$ \\
\hline & $\lambda_{\mathrm{Z}, n}=0.6 \mathrm{~W} /\left(\mathrm{m} .{ }^{\circ} \mathrm{C}\right)$ & $\lambda_{\mathrm{W}, n}=1.1 \mathrm{~W} /\left(\mathrm{m} .{ }^{\circ} \mathrm{C}\right)$ \\
\hline & $\lambda_{\text {air }, n}=200 \mathrm{~W} /\left(\mathrm{m}^{2} .{ }^{\circ} \mathrm{C}\right)$ & $V_{\mathrm{m}, \mathrm{STP}}=0.0224 \mathrm{~m}^{3} / \mathrm{mol}$ \\
\hline & $N_{\mathrm{uZ}, n}=4$ & $N_{\mathrm{uW}, n}=3.09$ \\
\hline & $C_{\mathrm{z}, n}=0.2917 \mathrm{kWh} /{ }^{\circ} \mathrm{C}$ & $C_{\mathrm{W}, n}=0.0205 \mathrm{kWh} /{ }^{\circ} \mathrm{C}$ \\
\hline & $\mu_{n g}=215$ \$/unit & $r_{\mathrm{ng}}=4380 \mathrm{~h}$ \\
\hline & $f_{\mathrm{ng}}=0.75 \mathrm{~m}^{3}$ & $P_{\mathrm{ng}}=0.5 \mathrm{~kW}$ \\
\hline & $\mu_{\mathrm{E}, n}=300 \$ / \mathrm{kW}$ & $r_{\mathrm{E}, \mathrm{n}}=10000 \mathrm{~h}$ \\
\hline & $\mu_{\mathrm{ESU}, n}=0.1353 \$ / \mathrm{on}$ & $\mu_{\mathrm{ESD}, n}=0.00682 \$ / \mathrm{off}$ \\
\hline \multirow{2}{*}{$\mathrm{NH}_{3}$ storage } & $V_{\mathrm{R}}=1.5 \mathrm{~m}^{3}$ & $V_{\mathrm{GS}, \text { min }}=V_{\mathrm{GS}, \max }=0.3 \mathrm{~m}^{3}$ \\
\hline & $S O C_{\mathrm{A}, \min }=0$ & $S O C_{\mathrm{A}, \max }=1$ \\
\hline \multirow{6}{*}{$\begin{array}{c}\text { Lead-acid } \\
\text { battery }\end{array}$} & $E_{\mathrm{R}}=10 \mathrm{kWh}$ & $\eta_{\mathrm{ch}}=\eta_{\mathrm{dis}}=91.4 \%$ \\
\hline & $\mu_{\mathrm{BES}}=150 \$ / \mathrm{kWh}$ & $r_{\mathrm{BES}}=1000$ cycles \\
\hline & $a_{1}=3291$ & $a_{2}=-4230$ \\
\hline & $a_{3}=4332$ & $a_{4}=-0.05922$ \\
\hline & $S O C_{\mathrm{BES}, \min }=0.1$ & $S O C_{\mathrm{BES}, \max }=0.9$ \\
\hline & $P_{\mathrm{ch}, \max }=2 \mathrm{~kW}$ & $P_{\mathrm{dis}, \max }=2 \mathrm{~kW}$ \\
\hline \multirow{2}{*}{ CHP } & \multicolumn{2}{|c|}{$S_{\mathrm{CHP}, \max }=5 \mathrm{~kW}$} \\
\hline & $\eta_{e, \mathrm{CHP}}=0.4$ & $\eta_{h, \mathrm{CHP}}=0.45$ \\
\hline Boiler & $S_{\mathrm{B}, \max }=3 \mathrm{~kW}$ & $\eta_{\mathrm{B}}=0.75$ \\
\hline Furnace & $S_{\mathrm{F}, \max }=3 \mathrm{~kW}$ & $\eta_{\mathrm{F}}=0.75$ \\
\hline Unit cost & \multicolumn{2}{|c|}{$\mu_{\mathrm{p}}=20 \$ / \mathrm{kWh}$} \\
\hline Algorithm & $\mathbf{d}_{w}=1$ & $\delta=0.1$ \\
\hline
\end{tabular}

B. Comparative Results and Analysis

For further analysis, four schemes are performed for comparisons: 1) Scheme 1 is the P2A driven energy hub framework in Sections II-IV; 2) Scheme 2 is the P2A driven energy hub framework without external heating from renewables in (12);3) Scheme 3 implements the optimal multi-energy utilization without considering battery and electrolyzer degradation cost in (20) and (21); 4) Scheme 4 is the conventional battery-solarwind operation scheme in previous researches [4],[5] where the P2A isn't considered.

With the temperature dynamics captured from the thermoelectrochemical model, the curves of reaction temperature and injected energy for electrolyzer heating obtained from schemes 1-4 are showed in Fig 4. It can be found that, since there are abundant wind and sunshine during noontime, the outputs of WT and PVT are utilized to heat the electrolyze for $\mathrm{NH}_{3}$ production enhancement. Scheme 1 is thus performed with very similar reaction temperature as scheme 3 and performed with higher reaction temperature than other schemes. Though without energy for electrolyzer heating, scheme 2 is still performed with higher reaction temperature than the ambient temperature due to the thermal interactions among inside reaction zone, wall, outside ambient environment. As a result of higher reaction temperature, electrolysis cells in scheme 1 stay high efficiency during noontime hours, and the solar and wind energy can be harvested and stored in the $\mathrm{NH}_{3}$ tank for later energy supplies during the on-peak hours.

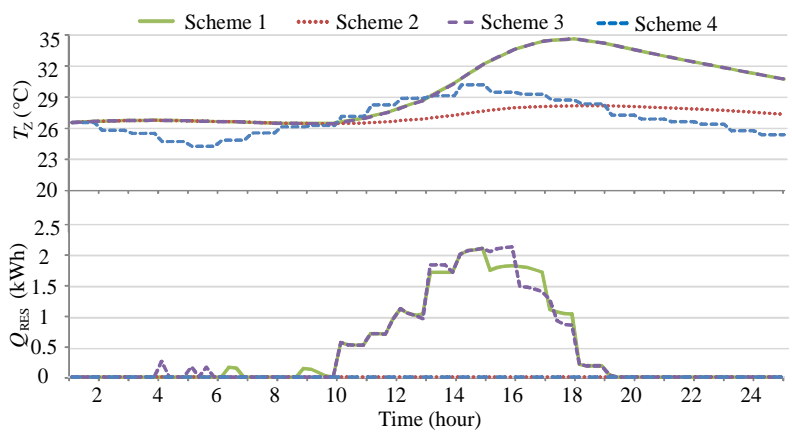

Fig. 4 The curves of daily reaction temperature and injected heating energy

Fig. 5-6 illustrate the output curves of multi-energy converters and storages with schemes 1-4. It can be found from Fig. 56 that compared with schemes 2-4, the proposed methodology can achieve a better coordination among battery, $\mathrm{NH}_{3}$ storage, and various energy conversion to improve system operational economy and renewable energy accommodation. For example, during the hours 23-24, the energy storages and CHP in scheme 1 stay at high outputs to follow the peak multi-energy loads. However, the outputs of CHP in scheme 2 and 3 are sharply decreased while the low-efficiency boiler and furnace increase their outputs. Also, multiple reverse discharging actions are implemented for battery in scheme 3 during the period of hours 5-15 since the degradation cost aren't considered. Furthermore, since there are abundant renewable generations during early morning (wind energy) and afternoon (solar energy), multienergy loads are mostly supplied with the electrical and thermal energy from WT and PVT. Compared with battery-only system in scheme $4, \mathrm{NH}_{3}$ tank and battery jointly serve as optional energy storages for excess renewable generations in scheme 1-3, and are prioritized as the reserve storage during hours 1-7 and hours 10-15, respectively. Also, instead of only using the battery and boiler, the CHP in schemes 1-3 serves as the main energy generation plants and adjust their outputs to follow the peak demands, while furnace and boiler function as supplement to fill the gaps between multi-energy loads and CHP outputs.

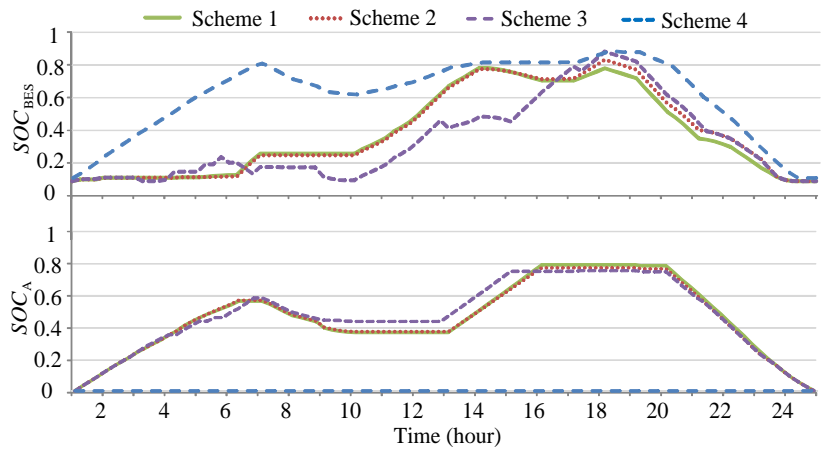

Fig. 5 The curves of daily battery $\mathrm{SOC}$ and $\mathrm{NH}_{3}$ storage outputs 


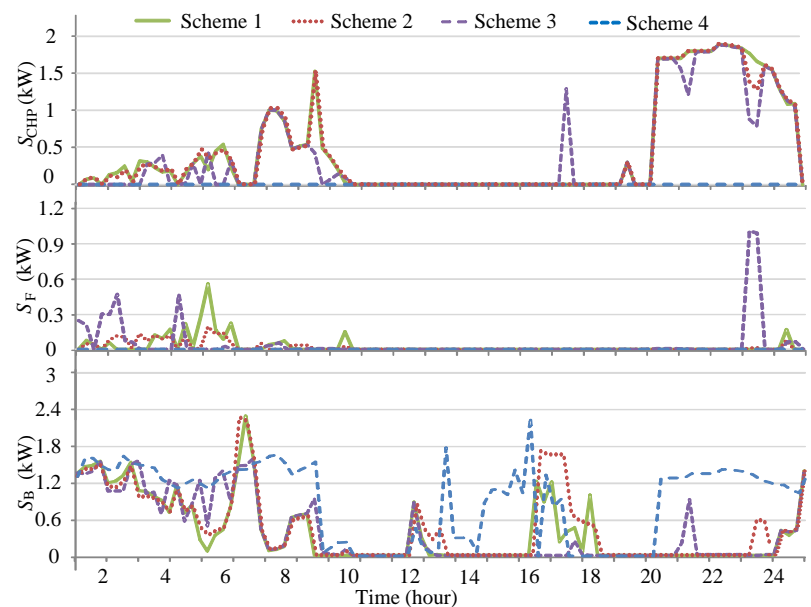

Fig. 6 The curves of outputs of multi-energy devices

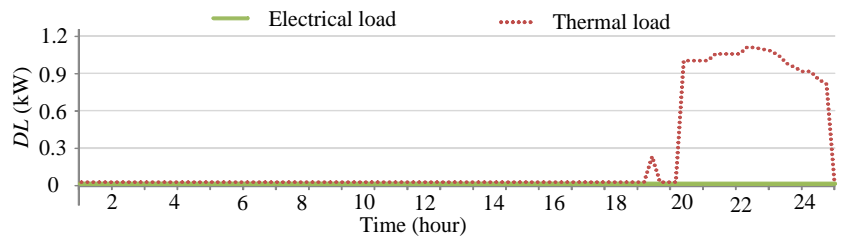

Fig. 7 The curves of load shedding with scheme 4

Table III quantitatively displays and compares the system operating costs, $\mathrm{NH}_{3}$ yield, battery/P2A degradation cost, running times, on/off times, load shedding, and solar-wind accommodation of schemes 1-4. Noted that the P2A degradation cost is calculated with the electrolyzer running hours and on/off times via (16) and (17). The contribution of renewables to the electrolyzer's heating, and thus to the reaction temperature, in scheme 1 results in an improvement in $\mathrm{NH}_{3}$ yield by $2.20 \%$ compared to the production performed by scheme 2 . On the other hand, it can be found that the multi-energy scheduling strategy can coordinate the charging/discharging of storages to reduce the system operating cost. As shown in Table II, the battery degradation cost contributes to a large share of the system operating cost. Because of the consideration of degradation cost in scheme 1, the battery charging/discharging and electrolyzer on/off actions are less frequent and more economical than that of scheme 3 at the expense of more running hours of electrolyzer. Fig. 7 illustrate the curves of electrical and thermal load shedding in scheme 4. Renewable energy in this scheme cannot be fully accommodated by the battery only, and heat load is curtailed during hours 20-24, which leads to considerably large battery degradation and system operating cost in Table III. In conclusion, the scheme 1 can provide flexible multi-energy utilization to accommodate solar-wind energy variability with least load shedding amounts.

TABLE III

COMPARATIVE PERFoRMANCE RESUlts WITH FOUR SCHEMES

\begin{tabular}{ccccc}
\hline \hline Scheme & 1 & 2 & 3 & 4 \\
\hline System operating cost (\$) & $\mathbf{4 . 4 0}$ & 4.45 & 6.73 & 137.07 \\
$\mathrm{NH}_{3}$ yield $\left(\mathrm{m}^{3}\right)$ & $\mathbf{6 . 5 1}$ & 6.37 & 5.89 & 0 \\
Battery degradation cost $(\$)$ & $\mathbf{2 . 8 6}$ & 2.91 & 4.74 & 7.42 \\
Electrolyzer running (hours) & 8.25 & 8.25 & 7.5 & 0 \\
Electrolyzer on/off (times) & 4 & 4 & 10 & 0 \\
P2A degradation cost $(\$)$ & $\mathbf{1 . 5 4}$ & 1.54 & 1.99 & 0 \\
Load shedding $(\mathrm{kWh})$ & $\mathbf{0}$ & 0 & 0 & 6.48 \\
Solar-wind accommodation $(\%)$ & $\mathbf{1 0 0}$ & 100 & 100 & 70.69 \\
\hline \hline
\end{tabular}

C. Discussion
The proposed P2A driven energy hub framework (Scheme 1) is compared with mainstream commercial alkaline electrolysis (AEL) and proton exchange membrane electrolysis (PEMEL) based P2G in [22] to demonstrate its benefits compared to regular P2G processes. Fig. 8 illustrates gas yield from the electrolyzer and the output of gas storage tank. Table IV gives the quantitatively comparisons with the battery and $\mathrm{P} 2 \mathrm{G}$ schemes over system operating cost, produced gas energy, battery/P2G degradation cost, running times, on/off times, load shedding, solar-wind accommodation, and renewable energy utilization efficiency. Noted that renewable energy utilization efficiency is referred as the ratio of the consumed multi-energy loads at the output port and the solar/wind energy at the input port within the energy hub. The promotion of renewable energy utilization efficiency indicates the optimization and enhancements of production, conversion, storage, and consumption of different energy carriers. It will help find the optimal coupling and energy conversion pathway among multiple energy carriers based on various criteria such as cost, energy efficiency, availability, and other parameters.

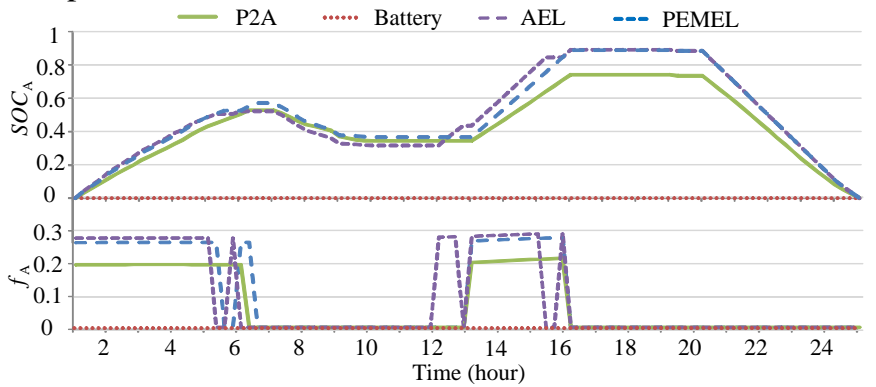

Fig. 8 The curves of daily $\mathrm{NH}_{3}$ storage $\mathrm{SOC}$ and yield

TABLE IV

COMPARATIVE PERFORMANCE RESUlTS OF P2G AND BATTERY TECHNIQUES

\begin{tabular}{ccccc}
\hline \hline Techniques & P2A & Battery & AEL & PEMEL \\
\hline System operating cost (\$) & $\mathbf{4 . 4 0}$ & 137.07 & 21.51 & 24.14 \\
Gas energy (kWh) & $\mathbf{2 8 . 2 5}$ & 0 & 27.89 & 27.44 \\
Battery degradation cost (\$) & $\mathbf{2 . 8 6}$ & 7.42 & 3.60 & 3.40 \\
Electrolyzer running (hours) & 8.25 & 0 & 7.75 & 8 \\
Electrolyzer on/off (times) & 4 & 0 & 10 & 6 \\
P2G degradation cost (\$) & $\mathbf{1 . 5 4}$ & 0 & 1.89 & 1.64 \\
Load shedding (kWh) & $\mathbf{0}$ & 6.48 & 0.80 & 0.95 \\
Solar-wind accommodation (\%) & $\mathbf{1 0 0}$ & 70.69 & 100 & 100 \\
Renewable utilization efficiency (\%) & $\mathbf{6 9 . 0 9}$ & 65.62 & 68.66 & 68.58 \\
\hline \hline
\end{tabular}

It can be found that more gas energy can be obtained from P2A scheme and the charging/discharging actions of battery are less frequent than that of conventional $\mathrm{P} 2 \mathrm{G}$ schemes, thereby prolonging the service life of energy storages. In addition to the required additional energy for liquefaction/compression processes and special costly storage tanks, the obtained gas from conventional P2G schemes cannot fulfil the multi-energy demands. Thus, the renewable utilization efficiency of $\mathrm{P} 2 \mathrm{~A}$ is slightly higher than other P2G schemes. It also can be found that, compared with battery scheme, renewable energy can be fully accommodated by all P2G driven energy hub schemes. In order to analyze the effects of battery capacity on the system performance, the battery capacity in scheme 4 is further increased to $50 \mathrm{kWh}$, and the load shedding would be gradually reduced to 0 at the capacity of $40 \mathrm{kWh}$. Though increasing to 50 $\mathrm{kWh}, 24.39 \%$ of renewable energy cannot be fully accommodated and the main renewable curtailment is the generating heat from PVT. Therefore, it is concluded P2A energy storage pro- 
vides an alternative solution to address the integration and utilization problems of high share of fluctuating and intermittent RESs.

In order to confirm its operational performance under extreme weather (e.g. cloudy day or rainy day) conditions, the proposed P2A scheme is further performed on a day without solar energy. Fig. 9 illustrates gas yield from the electrolyzer and the output of gas storage tank. Table $\mathrm{V}$ gives the quantitatively comparisons of scheduling results with the battery and P2G schemes. It can be found that, without the solar energy, all schemes cannot totally fulfil the multi-energy demands. Compared with other $\mathrm{P} 2 \mathrm{G}$ schemes, the propose $\mathrm{P} 2 \mathrm{~A}$ scheme still can obtain considerable gas energy to provide more multienergy demands with the least $\mathrm{P} 2 \mathrm{G}$ degradation cost. Thus, the proposed P2A scheme can improve the renewable energy utilization efficiency by at most $3.46 \%$. Meanwhile, though the battery scheme has the least load shedding amounts, it incurs more battery degradation cost, and thus increases the overall operating cost. Therefore, it is concluded that the proposed P2A scheme can provide overall superior performance for providing the multi-energy supplies under extreme weather conditions.

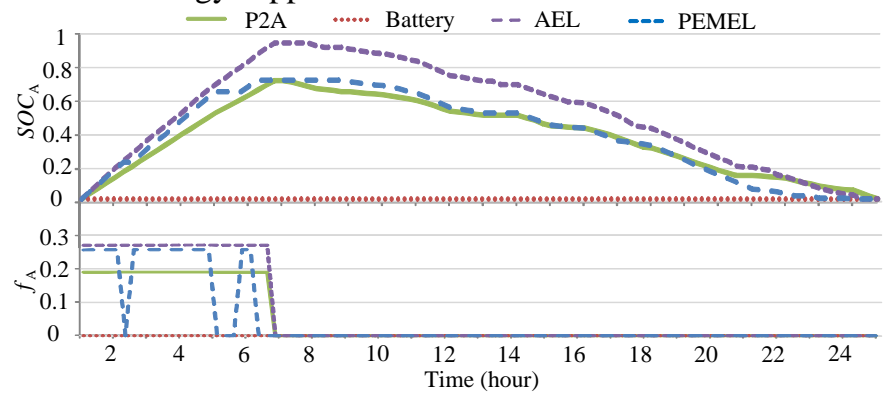

Fig. 9 The curves of daily $\mathrm{NH}_{3}$ storage $\mathrm{SOC}$ and yield on a day with no solar

TABLE V

COMPARATIVE PERFORMANCE RESUlTS OF P2G AND BATTERY TECHNiQUeS

\begin{tabular}{ccccc}
\hline \hline Techniques & P2A & Battery & AEL & PEMEL \\
\hline System operating cost (\$) & $\mathbf{1 0 6 4 . 2 3}$ & 1064.83 & 1094.27 & 1124.74 \\
Gas energy $(\mathrm{kWh})$ & 19.19 & 0 & $\mathbf{2 0 . 4 4}$ & 14.37 \\
Battery degradation cost $(\$)$ & 1.30 & 6.70 & $\mathbf{0 . 8 5}$ & 1.85 \\
Electrolyzer running (hours) & 5.75 & 0 & 5.75 & 4.25 \\
Electrolyzer on/off (times) & 2 & 0 & 2 & 6 \\
P2G degradation cost (\$) & $\mathbf{0 . 9 7}$ & 0 & 0.98 & 1.01 \\
Load shedding (kWh) & 53.10 & $\mathbf{5 2 . 9 0}$ & 54.62 & 56.09 \\
Solar-wind accommodation (\%) & $\mathbf{1 0 0}$ & 100 & 100 & 100 \\
Renewable utilization efficiency $(\%)$ & 87.52 & $\mathbf{8 7 . 7 4}$ & 85.76 & 84.06 \\
\hline \hline
\end{tabular}

\section{CONCLUSIONS}

In this paper, the $\mathrm{P} 2 \mathrm{~A}$ technology is utilized to form a multienergy coupling framework and provide a sustainable alternative energy storage solution to harvest the intermittent solarwind energy in the form of $\mathrm{NH}_{3}$. The short-term cycling properties of P2A are formulated as a generalized degradation cost model, which is further incorporated into the optimal multienergy utilization problem with an iterative scheduling scheme. It can be concluded from case studies that :1) With the thermoelectrochemical effects, the P2A contributes significantly to the overall energy system availability over both temporal (energy storage) and spatial (energy conversion) scales, and $\mathrm{NH}_{3}$ yield can be improved by $2.20 \%$; 2) The P2A storage can serve as an alternative to the battery, and thus largely decrease the system operating cost and battery degradation cost; 3) Compared with other P2G techniques, the proposed P2A scheme can improve the renewable energy utilization efficiency by at most $3.46 \%$, and also can be beneficial for the integration and utilization of high penetration of RESs.

\section{REFERENCES}

[1] P. Li, D. Yu, M. Yang and J. Wang, "Flexible look-ahead dispatch realized by robust optimization considering CVaR of wind power," IEEE Trans. Power Syst., vol. 33, no. 5, pp. 5330-5340, Sep. 2018.

[2] M. H. Nehrir, C. Wang, K. Strunz, et al., "A review of hybrid renewable/alternative energy systems for electric power generation: Configurations, control, and applications," IEEE Trans. Sustain. Energy, vol. 2, no. 4, pp. 392-403, Oct. 2011.

[3] Q. Chen, X. Zhao, and D. Gan, "Active-reactive scheduling of active distribution system considering interactive load and battery storage," Protection and Control of Modern Power Systems, vol. 2, no. 29, pp.1-11, Aug. 2017, DOI:10.1186/s41601-017-0060-2.

[4] C. Ju, P. wang, L Goel, et al., "A two-layer energy management system for microgrid with hybrid energy storage considering degradation costs," IEEE Trans. Smart Grid, vol. 9, no. 6, pp. 6047-6057, Nov. 2018.

[5] B. Zhou, X. Liu, and Y. Cao, et al., "Optimal scheduling of virtual power plant with battery degradation cost," IET Gen., Trans. Distrib., vol. 10, no. 3, pp. 712-725, Feb. 2016

[6] I. Duggal and B. Venkatesh, "Short-term scheduling of thermal generators and battery storage with depth of discharge-based cost model," IEEE Trans. Power Syst., vol. 30, no. 4, pp. 2110-2118, Jul. 2015.

[7] B. Zhou, D. Xu, C. Li, et al., "Optimal scheduling of biogas-solar-wind renewable portfolio for multi-carrier energy supplies," IEEE Trans. Power Syst., vol. 33, no. 6, pp. 6229-6239, Nov. 2018.

[8] J. Yang, N. Zhang, Y. Cheng, et al., "Modeling the operation mechanism of combined $\mathrm{P} 2 \mathrm{G}$ and gas-fired plant with $\mathrm{CO}_{2}$ recycling," IEEE Trans. Smart Grid, vol. 10, no. 1, pp. 1111-1121, Jan. 2019.

[9] S. Clegg and P. Mancarella, "Integrated modeling and assessment of the operational impact of power-to-gas (P2G) on electrical and gas transmission networks," IEEE Trans. Sustain. Energy, vol. 6, no. 4, pp. 1234-1244, Oct. 2015

[10] ISPT, "Power to Ammonia," Tech. Rep., 2016. http://www.ispt.eu/media/ISPT-P2A-Final-Report.pdf.

[11] Y. Bennani, A. Perl, A. Patil, et al., Power-to-ammonia: rethinking the role of ammonia - from a value product to a flexible energy carrier (FlexNH3), Groningen, Netherlands: Hanzehogeschool Groningen, 2016.

[12] J. Ikäheimo, J. Kiviluoma, R. Weiss, et al., "Power-to-ammonia in future North European 100\% renewable power and heat system," Int. J. Hydrog. Energy, vol. 43, no. 36, pp. 17295-17308, Sep. 2018.

[13] X. Xue, R. Chen, C. Yan, et al., "Review on photocatalytic and electrocatalytic artificial nitrogen fixation for ammonia synthesis at mild conditions: advances, challenges and perspectives," Nano Res., DOI: 10.1007/s12274 018-2268-5, 2018

[14] J. Hou, M. Yang, and J. Zhang, "Recent advances of catalysts, electrolytes and electrode engineering for Nitrogen reduction reaction at ambient conditions," Nanoscale, DOI:10.1039/D0NR00412J, 2020.

[15] D. Frattini, G. Cinti, G. Bidini, et al., "A system approach in energy evaluation of different renewable energies sources integration in ammonia production plants," Renew. Energy, vol. 99, pp. 472-482, Dec. 2016.

[16] A. Allman and P. Daoutidis, "Optimal scheduling for wind-powered ammonia generation: effects of key design parameters," Chem Eng Res Des , vol. 131, pp. 5-15, Mar. 2018.

[17] A. Allman, D. Tiffany, S. Kelley, et al., "A framework for ammonia supply chain optimization incorporating conventional and renewable generation," AIChE J., vol. 63, no. 10, pp. 4390-4402, Oct. 2017.

[18] S. Beerbühl, M. Frohling, and F. Schultmann, "Combined scheduling and capacity planning of electricity-based ammonia production to integrate renewable energies," Eur. J. Op. Res., vol. 241, no. 3, pp. 851-862, Mar. 2015.

[19] J. Wang, J. Wang, P. Zhao, and Y. Dai, "Proposal and thermodynamic assessment of a new ammonia-water based combined heating and power (CHP) system," Energy conversion and management, vol. 184, no. 15, pp. 277-289, Mar. 2019.

[20] A. Ursua, L. Gandia, and P. Sanchis, "Hydrogen production from water electrolysis: current status and future trends," Proc. IEEE, vol. 100, no. 2, pp. 410-426, Jan. 2012.

[21] J. Udagawa, P. Aguiar, and N. P. Brandon, "Hydrogen production through steam electrolysis: Model-based steady state performance of a cathodesupported intermediate temperature solid oxide electrolysis cell," J. Power Sources, vol.166, no. 1, pp. 127-136, Mar. 2007. 
[22] A. Buttler and H. Spliethoff, "Current status of water electrolysis for energy storage, grid balancing and sector coupling via power-to-gas and power-to-liquids: a review," Renew. Sustain. Energy Rev., vol.82, no. 3, pp. 2440-2454, Feb. 2018.

[23] A. Schulte-Schulze-Berndt and K. Krabiell, "Nitrogen generation by pressure swing adsorption based on carbon molecular sieves," Gas Separation \& Purification, vol.7, no. 4, pp. 253-257, 1993.

[24] R. Lan, J. Irvine, S. Tao, "Synthesis of ammonia directly from air and water at ambient temperature and pressure," Sci. Rep., vol. 3, no. 1445, pp. 1-7, Jan. 2013

[25] F. Garcia-Torres and C. Bordons, "Optimal economical schedule of hydrogen-based microgrids with hybrid storage using model predictive control," IEEE Trans. Ind. Electron.,vol. 62, no. 8, pp. 5195-5207, Aug. 2015.

[26] S. Thakare, K. Priya, C. Ghosh, and S. Bandyopadhyay, "Optimization of photovoltaic-thermal based cogeneration system through water replenishment profile," Solar Energy, vol. 133, pp. 512-523, Aug. 2016.

[27] H. Hao, D. Wu, J. Lian and T. Yang, "Optimal coordination of building loads and energy storage for power grid and end user services," IEEE Trans. on Smart Grid, vol. 9, no. 5, pp. 4335-4345, Sep. 2018.

[28] P. Hou, J. Hu, and G. Yang, "Convex optimization of virtual storage system scheduling in market environment," J. Mod. Power Syst. Clean Energy, vol. 7, pp. 1744-1748, Jul. 2019.

[29] W. J. Mai and C. Y. Chung, "Economic MPC of aggregating commercial buildings for providing flexible power reserve," IEEE Trans. Power Syst., vol. 30, no. 5, pp. 2685-2694, Sep. 2015.

[30] D. Xu, Q. Wu, B. Zhou, et al. "Distributed multi-energy operation of coupled electricity, heating and natural gas networks," IEEE Trans. Sustain. Energy, DOI: 10.1]109/TSTE.2019.2961432, in press, 2020.

[31] S. Boyd, N. Parikh, E. Chu, et al., "Distributed optimization and statistical learning via the alternating direction method of multipliers," Found. Trends Mach. Learn., vol. 3, no. 1, pp. 1-122, Jul. 2011.

[32] T. Trifonov, "Coordination of battery energy storage and power-to-gas in distribution systems," Protection and Control of Modern Power Systems, vol. 2, no. 38, pp.1-8, Nov. 2017, DOI: 10.1186/s41601-017-0072-y.

[33] Chemical Lab Use 6Nm3/h, Purity 99.9\% Small PSA Nitrogen Generator [Online]. Available: https://www.alibaba.com/product-detail/ChemicalLab-Use-6Nm3-h-

Purty_60697960137.html?spm=a2700.7724857.normalList.125.2d3872b4 OIeLG4

[34] Multi-Year Research, Development and Demonstration Plan, U.S. Department of Energy (DOE), Washington, DC, USA, 2006.

[35] X. Zhang. M. Shahidehpour, A. Alabdulwahab, and A. Abusorrah, "Optimal expansion planning of energy hub with multiple energy infrastructures," IEEE Trans. Smart Grid, vol. 6, no. 5, pp. 2302-2311, Sep. 2015.

[36] GAMS [Online]. Available: http://www.gams.com/. 